\title{
PENDAMPINGAN IBU BEKERJA TERHADAP PENGGUNAAN YOUTUBE PADA ANAK
}

\author{
Fasiyah Noor ${ }^{1}$, Restu Ayu Mumpuni ${ }^{2}$, Indah Laksmiwati ${ }^{3}$, Anita Amaliyah ${ }^{4}$ \\ 1,2,3,4Program Magister Ilmu Komunikasi Universitas Diponegoro \\ Jl. Erlangga Barat 7 no.33, Semarang Jawa Tengah 50241 \\ Email : 'Fasyiahn@gmail.com
}

\begin{abstract}
ABSTRAK
Media sosial, terutama YouTube menjadi bagian utama dari kehidupan kita seharihari dan sebagian besar anak-anak di bawah umur (0-13 tahun). Di Indonesia, pengguna dibawah umur berada di peringkat kedua dan mereka menggunakannya secara teratur dengan perangkat orang tua, terutama para ibu. Bahaya untuk pengguna dibawah umur tanpa nasihat orang tua termasuk risiko terhadap: keselamatan pribadi, akses pada hal yang mengganggu, merugikan, konten tidak pantas, isolasi sosial, dan kurang tidur. Ini adalah risiko sebagai akibat dari pengawasan terbatas dari orang tua dan keluarga dewasa yang tidak cukup berpengalaman dalam prosedur keselamatan online.

Penelitian ini menjelaskan tentang peran ibu saat bekerja pada apakah mereka mengontrol penggunaan media sosial oleh anak-anak mereka. Tujuan dari penelitian ini adalah untuk menunjukkan bagaimana ibu bekerja mengelola akses YouTube dan pola pendampingan anak-anak mereka yang masih dibawah umur di rumah terkait konten yang ditonton dan kebiasaan media mereka.

Metode penelitian ini adalah mix method dengan jumlah 57 responden di Kota Semarang. Hasil penelitian menunjukkan bahwa ibu bekerja memiliki peran yang besar dan positif. Akses YouTube diberikan para ibu pada hanya saat didampingi ibu, hanya saat hari libur dan sebagian memberikan akses setiap hari namun disertai pengawasan. Para ibu bekerja melakukan pendampingan berupa : 1) memilihkan channel yang akan ditonton; 2) mengawasi anak ketika mengakses YouTube; 3) memberikan batasan konten YouTube yang akan ditonton; dan 4) melakukan diskusi mengenai konten yang telah ditonton.
\end{abstract}

Kata kunci: Social Media, YouTube, Peran Ibu bekerja

\begin{abstract}
Social media, especially YouTube become a major part of our daily lives and mostly underage children (0-13 y.o). In Indonesia, underage users are ranked in second place and they are using it regularly with parent's device, particularly moms. The dangers for underage user without parental advice include risk towards: personal safety, access to disturbing, harming, inaoppropriate material, social isolation, and poor sleep. These are risk as a result of limited supervision from parents and adult family who are not adequately versed in onine safety procedures.

This research explains the role of working mom on whether they control the use of social media by their children. The purpose of this research is to show how working mom managing YouTube access and the patterns of mentoring their underage children at home regarding the content being watched and their media habits.

This research method is quantitative descriptive with a number of 57 respondents in the city of Semarang. The results showed that working mom have a large and positive role. YouTube access is given by mothers only when accompanied by mothers, only on holidays and some provide access every day but accompanied by supervision. The working moms provide assistance in the form of: 1) choosing the channel to watch; 2) supervise children
\end{abstract}


when accessing YouTube; 3) provide limits on the YouTube content that will be watched; and 4) discuss the content that has been watched.

Keywords: Social Media, YouTube, Working Mom

\section{A. PENDAHULUAN}

Perkembangan sosial media serta loT (Internet of Things) menjadikan masyarakat menggunakan akses digital lebih sering dibandingkan dulu yang masih berkutat dengan offline. Mulai dari akses berita hingga akses tontonan hiburan; masyarakat seakan tidak dapat terpisah dengan dunia digital. Indonesia, dengan jumlah penduduk lebih dari 250 juta orang dan $70 \%$ rata-rata mengakses internet atau dunia digital setiap hari ("Digital 2019: Indonesia - DataReportal - Global Digital Insights," 2019).

Dari sekian platform sosial media yang ada, YouTube menempati urutan pertama dalam segi akses yaitu $88 \%$ lalu kemudian disusul WhatsApp sebesar 83\% (Ibid). RataRata masyarakat menghabiskan waktu untuk mengakses internet dalam hal melihat konten video online, video on demand sekitar 3 hingga 4 jam tiap harinya atau sekitar 17\% waktu yang dihabiskan untuk menjelajah internet dan sosial media. Alasan dalam mengakses internet dan sosial media tentu saja berbeda bagi masing-masing individu, namun yang perlu kita garis bawahi saat ini ada sebanyak $85 \%$ populasi rural Indonesia yang juga telah menggunakan YouTube. Hal ini didasari karena adanya faktor seperti penyediaan infrastruktur internet dan koneksi yang lebih berkualitas, harga sarana mengakses internet seperti paket data yang semakin terjangkau, serta konten yang sesuai dengan minat pengguna internet masyarakat.

Pertumbuhan konsumsi internet oleh anak-anak menempati urutan kedua setelah usia remaja ("Digital 2019: Indonesia DataReportal - Global Digital Insights," 2019) menjadikan sebuah fakta yang kini menjadi bahasan dan resistensi di masyarakat dan tentunya pendidikan dan pengetahuan tentang bagaimana mengakses internet secara aman tentu sangat dibutuhkan
(Tur-Viñes, Núñez-Gómez, \& González-Río, 2018).

YouTube merupakan salah satu platform yang menggunakan online video sharing; aksesnya tidak terbatas (unlimited) yang berada pada hampir 88 negara dengan beragam bahasa yang tentu menjadi daya tarik tersendiri bagi anak-anak yang merupakan konsumen audio-visual terbesar. Pada kenyatannya anak-anak terlebih yang berumur dibawah 8 tahun memandang bahwa internet merupakan sumber utama untuk hiburan, bukan lagi media konvensional, yaitu TV (Helsper, Kalmus, Hasebrink, Sagvari, \& De Haan, 2013). Namun, jika melihat perkembangannya, maka TV konvensional pun sekarang membuat profil di YouTube dan mengunggah konten-konten dari acara TV ke YouTube sehingga membuat video tidak hanya dihasilkan dari content creator saja tapi juga TV itu sendiri. Riset menyatakan bahwa anak-anak lebih mudah memiliki kecanduan internet dibandingkan dengan orang dewasa (Mas et al., 2018) especially students, become more addicted to it. This is a perturbative topic that needed to be tackled. Hence, a study is conducted involving secondary school students in Pasir Mas, Kelantan in order to observe the level of internet dependency among them. A total of 352 students from the age of 13 until 19 years old are selected as respondents. This study uses descriptive analysis by reporting the results of the study in the form of frequency and percentage to determine the level of internet dependency among local students. The research instrument in the form of an Internet Addiction Test questionnaire is modified by a researcher from the Internet Addiction Test (IAT.

Dampak YouTube terhadap anak-anak dibawah umur (dibawah 13 tahun) bisa menjadi negatif dan juga positif. Hal positif 
yang bisa didapatkan adalah kemampuan untuk berkembangnya skill komunikasi interpersonal (Putra \& Patmaningrum, 2018). Namun, dampak negatif YouTube juga perlu diwaspadai; diantaranya adalah konten yang berbau pornografi, seks, tontonan yang berisi kekerasan dan juga kebencian (Ofcom, 2019). Hal ini diperkuat dari beberapa penelitian sebelumnya yang juga menyatakan bahwa anak-anak sangat sensitif terhadap tontonan yang menunjukkan kekerasan, menunjukkan korban kejahatan, serta kegiatan bullying (Livingstone, Kirwil, Ponte, \& Staksrud, 2013).

Meski YouTube telah menyediakan platform khusus anak-anak yaitu YouTube Kids, namun nyatanya masih ditemukan konten negatif seperti video penembakan, pembunuhan dan lain sebagainya (Orphanides, 2018). Sehingga lingkup terdekat anak-anak yang saat ini harus peduli dengan konten yang dikonsumsi oleh anak-anak mereka yaitu keluarga, dan tentu saja lbu menjadi salah satu aspek yang paling penting bagi anak-anak yang sering mengakses YouTube.

Tentunya lbu full time dirumah sangat berbeda dengan ibu bekerja. Para ibu pekerja harus membagi waktu dengan keluarga dan anak- anak mereka atas pekerjaan yang mereka miliki. Ibu merupakan salah satu faktor lingkungan keluarga yang berpengaruh pada tumbuh kembang, memainkan peran di dalam mendidik anak terutama pada masa balita hingga ibu sebagai teladan atau "model" peniruan anak dan sebagai pemberi stimulasi bagi perkembangan anak (Putri \& Kusbaryanto, 2012).

Di artikel ini kami akan membahas bagaimana pentingnya peran orang tua terutama Ibu bekerja dalam mengelola akses YouTube pada anak-anak mereka. Juga pendampingan ibu bekerja pada anakanak mereka yang masih dibawah umur dirumah mengenai konten yang ditonton dan kebiasaan media mereka. Selain itu, di artikel ini juga akan membahas mengenai sejauh mana pengetahuan Ibu bekerja dalam meminimalisir dampak negatif YouTube.

\section{B. TINJAUAN PUSTAKA}

\section{Uses \& Gratification Theory}

Teori Uses and Gratification dapat digunakan untuk mermahami eksposur ke media. Teori ini berfokus pada mengapa orang menggunakan media dan untuk apa mereka menggunakannya. Audiens dianggap aktif dan dianggap berorientasi pada tujuan. Audiens sangat bertanggungjawab dalam memilih media untuk memenuhi kebutuhan mereka sendiri. Teori ini sesuai untuk menjelaskan bahwa pengguna media berperan aktif dan menyadari pilihan dan keputusan dalam interaksi dengan media mereka (Littlejohn, Foss, \& Oetzel, 2017).

Selama bertahun-tahun, beberapa tipologi gratifikasi telah diperoleh dari berbagai publikasi penelitian. McQuail, Blumier, dan Brown dalam McQuail (2010) mengkategorikan interaksi orang-orang media dalam empat tipologi: pengalihan (melarikan diri dari rutinitas atau masalah, pelepasan emosional), hubungan pribadi (pertemanan; utilitas sosial), pembentukan identitas pribadi (referensi diri; eksplorasi realitas; penguatan nilai), dan pengawasan (bentuk pencarian informasi). Ada 5 skala untuk mengukur lima dimensi kepuasan: pencarian informasi, utilitas keputusan, hiburan, utilitas antarpribadi, dan interaksi parasosial (Rossi, n.d.).

Meskipun ada kritik pada penyederhanaan tipologi gratifikasi semacam itu, penelitian U\&G saat ini terus mengkategorikan motivasi untuk penggunaan media dalam hal pengalihan (yaitu, sebagai pelarian dari rutinitas atau untuk pelepasan emosional), utilitas sosial (yaitu, untuk memperoleh informasi untuk percakapan) identitas pribadi (yaitu, untuk memperkuat sikap, kepercayaan, dan nilainilai), dan pengawasan (yaitu, untuk belajar tentang komunitas seseorang peristiwa, dan urusan politik). Itupun yang dijelaskan oleh Ruggiero (2000) setelah mempelajari 
penelitian-penelitian sebelumnya mengenai teori penggunaan dan gratifikasi. Dia berargumen bahwa penggunaan teori uses and gratification adalah pendekatan yang tepat untuk dua hal : 1) komunikasi melalui teknologi komputer dan 2) fase awal dari sarana media massa baru.

Beberapa motivasi menggunakan smartphone yang dalam hal ini akses pada YouTube menurut Brooks (2011) dalam Irmayanti (2018) mengungkapkan bahwa orangtua memberikan gawai kepada anak karena beberapa alasan, seperti menenangkan anak saat rewel, membuat anak mudah tidur atau makan, dan memberikan waktu luang bagi orangtua agar dapat melakukan perkerjaan rumah tangga atau bersantai. Namun menurut Santy dan Irtanti (2017) bahwa pola asuh permisif yang digunakan oleh orangtua dalam menghadapi anak temper tantrum cenderung membuat anak menjadi manja dan terbiasa mendapatkan apa yang diinginkan. Sehingga anak akan memberontak dan meledakkkan emosinya (temper tantrum) untuk mendapatkkan apa yang diinginkan. (Irmayanti, 2018)

\section{Sosial Media}

Media sosial adalah istilah yang sering digunakan untuk merujuk pada bentuk media baru yang melibatkan partisipasi interaktif (Manning, 2014). Seringkali perkembangan media dibagi menjadi dua zaman yang berbeda, usia siaran dan usia interaktif. Di era penyiaran, media hampir secara eksklusif terpusat di mana satu entitas - seperti stasiun radio atau televisi, perusahaan surat kabar, atau studio produksi film yang digunakan untuk mendistribusikan pesan ke banyak orang.

Saat ini $43 \%$ dari seluruh populasi lbu mengakses internet dan sosial media, dan penggunaan TV sangat jauh berkurang dibandingkan dengan akes YouTube bagi para ibu ("Indonesian Digital Mums Survey 2017 by theAsianparent - issuu," n.d.). Ibu pengguna internet di Indonesia menggunakan internet masih dalam pola identitas mereka sebagai orang tua dimana topik yang mereka cari ketika mengakses internet adalah tips mengenai menjadi orang tua, memasak, berita, pendidikan, kesehatan dan juga gaya busana dan selebritas (ibid). Hal ini merupakan bagian dari perkembangan era digital dan tentunya jika Ibu juga well-educated maka akan membantu dalam mencegah segala dampak buruk baik secara kesehatan dan psikologis akibat dunia digital.

Kemudahan akses serta informasi terhadap dunia digital mempermudah adanya interaksi sosial, komunikasi, kecepatan sebagai masyarakat digital (digital native). Tentu saja, hal ini tidak hanya berlaku pada Ibu, namun juga anakanak yang terlahir pada era digital juga merupakan bagian dari hidup mereka. Tak jarang kita bisa melihat foto masa kehamilan hingga kelahiran (maternal shots, birth shots) diunggah ke sosial media hingga tumbuh kembangnya si anak terlebih anakanak yang tumbuh di kota-kota besar (urban society).

\section{Sosial Media dan Anak-anak}

Penggunaan media sosial sangat populer dan bagi banyak orang muda itu telah menjadi rutinitas sehari-hari. Saat menggunakan internet, anak-anak terpapar pada konten yang memengaruhi sikap mereka. Dengan cara itu media massa menjadi lingkungan pendidikan yang penting. Anak-anak menempati urutan kedua dalam hal akses intenet di Indonesia ("Digital 2019: Indonesia - DataReportal Global Digital Insights," 2019).

Sosial media dapat berdampak pada pendidikan pada anak-anak karena banyaknya waktu yang dihabiskan oleh mereka untuk mengakses dunia digital (Godawa, Gurba, Rzewucka, Tabor, \& Gurba, 2019). Meski tentu saja banyak penelitian yang menyatakan bahwa dunia digital berpengaruh terhadap pembentukan sikap pro-sosial anak-anak, namun pada saat yang sama banyak sekali contoh negatif yang bisa terdampak pada anak dalam kehidupan dan perkembangan sosial (Orphanides, 2018).

Penelitian di banyak Negara menyatakan bahwa anak-anak dibawah usia 13 tahun, penggunaan gawai (gadget) masih sangat 
dikendalikan oleh orang tua mereka dimana hanya $30 \%$ saja mereka diberikan kepercayaan oleh orang tua mereka untuk mermbawa atau memiliki gawai sendiri (Ofcom, 2019). Mayoritas anak-anak ketika mendapatkan akses terhadap gawai (gadget) banyak mengakses YouTube dan bermain video games (ibid).

Aktifitas anak-anak dalam mengakses sosial media tentu saja tidak lepas dari peran serta orang tua terutama ibu. Hal ini tentu saja sangat berbeda jika kita melihat 5-10 tahun yang lalu, dimana media tradisional seperti TV yang menjadi primadona hiburan bagi anak-anak ketika teknologi tidak berkembang jauh seperti sekarang. Hal ini mengindikasikan bahwa adanya pergeseran paradigma sosial pada anak-anak dalam kehidupan sehari-hari yang tentu saja bisa berdampak baik maupun buruk.

Perubahan perkembangan media tentu saja berdampak bagi semua orang terlebih anak- anak, dimana dulu media platform audio visual hanya bertumpu pada TV, hingga sekarang menjadi streaming video (video on demand) seperti di YouTube (Campbell, 2017). Dunia digital merupakan sumber informasi tanpa batas sehingga seseorang bisa menghabiskan waktu berjam-jam dengan gawai mereka. Gawai (gadget) seperti mobile phone, tablet, computer merupakan platform utama yang digunakan oleh anak-anak dalam akses dunia digital. Penelitian juga menunjukkan bahwa anak-anak lebih menghabiskan waktu berjam-jam dengan gadet mereka pada streaming video (video on demand) di YouTube dibandingkan dengan melihat TV (Miner, 2015).

Anak-anak dalam dunia digital sangat rentan terhadap aspek negatif diantaranya adalah terpaan atas konten-konten berbau pornografi. Pelecehan online hingga terkait dampak psikologis yaitu kecanduan internet (Guan \& Subrahmanyam, 2009). Tidak hanya itu, kecanduan internet lewat gawai atau gadget juga dapat menimbulkan ketidakstabilan perkermbangan turnbuh otak anak-anak (Taylor, 2017).

\section{Peran Orang Tua dan Ibu Pekerja}

Bertambahnya pengguna internet diikuti dengan bertambahnya dampak negatif yang ditimbulkannya. Beberapa kasus yang dilaporkan di antaranya pornografi dan cyberbullying. Hal inilah yang mengancam semakin banyak anakanak, dimana pengguna internet di usia anak-anak di seluruh dunia semakin banyak bahkan pada usia yang lebih muda, mereka menggunakan sarana mengakses dengan gadget yang semakin beragam (Livingstone, 2012).

Orang tua berperan penting dalam melindungi anaknya terhadap ancaman dampak negatif internet. Peran orang tua ini telah banyak dikaji dalam banyak literatur yang membuktikan bahwa orang tua adalah penyedia pondasi yang paling aman dalam perkembangan anaknya serta memiliki pengaruh yang sangat besar pada sikap dan tingkah laku anak. Seperti temuan dalam Putra dan Patmaningrum (2018) yang menemukan bahwa anakanak yang mengakses YouTube sebagai media untuk belajar, mencari informasi dan sebagai hiburan dengan pengawasan dan pembatasan penggunaan oleh orang tua memberikan dampak perkembangan baik pada komunikasi interpersonal (Putra \& Patmaningrum, 2018).

Pada dasarnya, dampak sosial media bisa menjadi positif ataupun negatif tergantung bagaimana para guru atau pendidik maupun orang tua anak mengarahkan. Manajemen penggunaan sosial media dari segi tanggung jawab dan waktu penggunaan tersebut sangatlah penting sehingga butuh banyak peran seluruh masyarakat terutama orang dewasa untuk bisa membimbing anak anak dalam usia sekolah dasar tersebut. (Ayodele, Mosunmola, Senanu, \& Aderonke, 2015) a survey of undergraduate students of a private university in southwest Nigeria was conducted. Survey results were analyzed using structural equation modeling (SEM Anak-anak yang memperoleh pendidikan yang terencana dengan baik dan berkualitas di dalam keluarga cenderung untuk 
belajar lebih banyak dan lebih siap untuk menguasai permintaan atau tuntutan yang kompleks dari sekolah formal.

Keluarga mempunyai peran yang sentral untuk membentuk karakter anak. (Rahmat, 2018). Orang tua perlu menerapkan beberapa strategi agar tetap bisa menguasai teknologi tanpa terpengaruh dampak negatifnya seperti orang tua membuat kesepakatan penggunaan gadget dan waktu penggunaanmya dan mendampingi serta memantau aktifitas anak dalam mengakses YouTube (Mulyono, 2016). Orang tua harus menunjukkan tanggungjawab yang ekstra dalam membimbing anak-anak menggunakan perangkat digital. Orang tua tidak boleh menyerahkan sepenuhnya kepada anak dalam menggunakan perangkat digital. Komunikasi internal dalam sebuah keluarga dan peran orang tua adalah faktor penentu dan dominan untuk melindungi anak dari dampak negatif. (Rahmat, 2018)

Dalam keluarga yang mendukung gender non-tradisional, dimana ibu tidak harus selalu dirumah dalam makna bisa bekerja di luar rumah maka peran ibu dalam menyeimbangkan dan mengintegrasikan peran ganda ibu dan bekerja sangat penting bagi anak-anak. Seperti yang digambarkan oleh Claretta dan Arianto (2018) tentang model pendampingan lbu pada Anak dalam Menggunakan Internet:

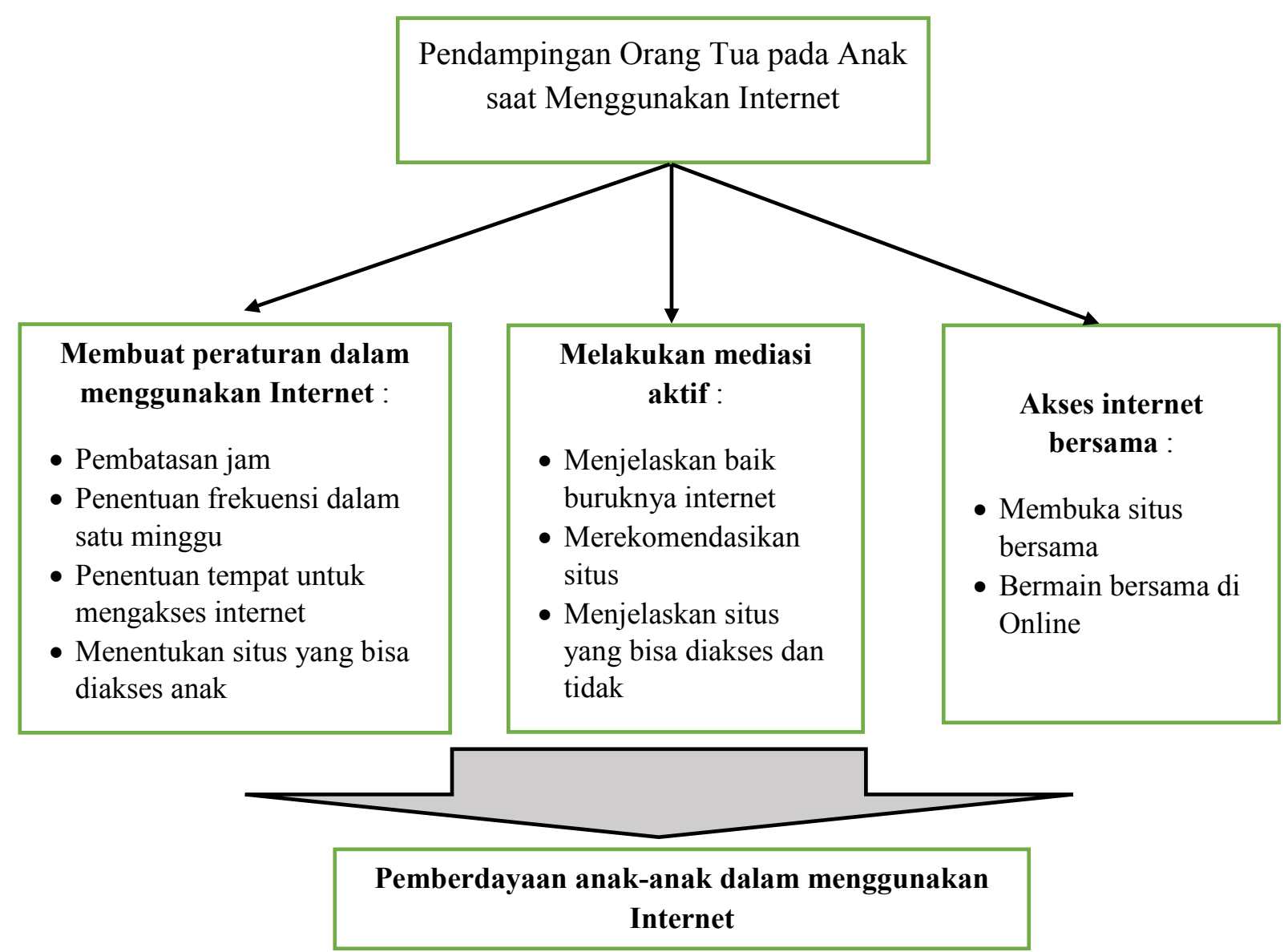

Gambar 1. Model Pendampingan Ibu pada Anak dalam Menggunakan Internet Sumber : (Claretta \& Arianto, 2018)

\section{METODE}

Tipe penelitian yang digunakan adalah deskriptif kuantitatif dan kualitatif (mix method). Penggunaan Kuesioner dilakukan dengan teknik random sampling dan wawancara dilakukan dengan snowball sampling.

Tautan google docs yang merupakan kuesioner online berisi 25 pertanyaan disebar melalui media sosial whatsapp, 
selanjutnya dilakukan wawancara kepada 10 responden yang juga mengisi kuesioner untuk mengkonfirmasi jawaban serta memperdalam hasil temuan penelitian. Partisipan dalam penelitian ini adalah berjumlah 57 orang perempuan yang aktif bekerja dan memiliki anak dibawah usia 13 tahun di Kota Semarang.

Tabel 2. Data Demografi Responden $(\mathrm{N}=57)$

\begin{tabular}{lcc}
\hline \multicolumn{1}{c}{ Keterangan } & Jumlah & Persen \\
\hline Umur (tahun) & & \\
$35-45$ & 41 & $71,9 \%$ \\
$30-35$ & 8 & $14,05 \%$ \\
$25-30$ & 8 & $14,05 \%$
\end{tabular}

Latar Belakang Pendidikan

$\begin{array}{lcc}\text { S3 atau lebih } & 1 & 2 \% \\ \text { S2 } & 11 & 19 \% \\ \text { S1/D4 } & 24 & 42 \% \\ \text { D3/D2/D1 } & 21 & 37 \% \\ \text { Durasi Akses } & \\ <1 \text { jam } & 39 & 68 \% \\ >1 \text { jam } & 18 & 32 \%\end{array}$

Gadget yang digunakan untuk mengakses YouTube

\begin{tabular}{lcc} 
Mobile Phone/HP & 52 & $91 \%$ \\
Komputer/PC & 4 & $7 \%$ \\
Tablet/lpad & 1 & $2 \%$ \\
\hline
\end{tabular}

\section{TEMUAN}

Hasil penelitian ini menggambarkan atau mendeskripsikan pola-pola dalam mengkonsumsi media sosial YouTube yang dilakukan anak-anak yang disertai pendampingan ibu dalam mengatur konsumsi konten dan frekuensi yang ditonton oleh anak-anak di bawah 13 tahun.

\section{Pola kebiasaan mengakses YouTube untuk anak}

Dari 57 responden, 4 responden menyatakan bahwa anak mereka tidak mengetahui Youtube. Sisanya, 53 orang atau 93\% responden mengetahui dan familiar dengan Youtube sehingga tidak asing untuk mengaksesnya. Berikutnya, hasil yang disebutkan adalah responden yang mengetahui dan mengakses Youtube, dimana mereka mengakses Youtube menggunakan Gadget orang tua (37 anak, 65\%), gadget pribadi (15 anak, 26\%) dan gadget teman (1 anak, 2\%). Selain menggunakan gadget, mereka juga terkadang mengaksesnya melalui komputer dirumah mereka.

Anak-anak terbiasa mengakses Youtube hanya ketika didampingi ibu mereka dirumah (25 anak, 44\%), ketika libur akhir pekan atau libur panjang (10 anak,17\%), dan setiap hari (14 anak, 24\%) dan lainnya hanya saat disekolah (dikelas dalam pembelajaran), saat dibutuhkan dan saat bosan dengan suasana dirumah dengan pendampingan orang tua.

Para ibu bekerja memberikan akses mengkonsumsi tayangan Youtube dengan tujuan hiburan 39 anak, 69\%. Selain tujuan hiburan responden sepakat motivasi lainnya seperti agar tidak rewel atau menangis (9 anak, 16\%), untuk tujuan mengerjakan tugas/PR (19 anak, 34\%), dan untuk belajar mengenai sesuatu (How To) berbentuk tutorial (4 anak, 7\%). Channel Youtube yang sering ditonton anak-anak adalah bermacam-macam dan sangat variatif namun masih dalam kategori tontonan anak (kartun, vlog how to, youtube kids, dsb) dan hanya sebagian kecil yang menonton channel atta halilintar dan ria ricis.

\section{Pola pendampingan Ibu pada anak dalam mengakses YouTube}

Beberapa tindakan yang dilakukan oleh ibu-ibu bekerja terhadap anak mereka menunjukkan pola pendampingan yang berjalan dengan baik bahkan cenderung ketat. Dari hasil penelitian ditemukan bahwa mayoritas Ibu terlibat aktif dalam pola pendampingan terhadap anak dalam mengakses Youtube, seperti data dibawah ini : 
Tabel 3. Pola Pendampingan Ibu bekerja pada anak dalam mengakses Youtube

\begin{tabular}{lccc}
\hline \multicolumn{1}{c}{ Bentuk pendampingan lbu bekerja } & Ya, Sering & Jarang & Tidak pernah \\
\hline $\begin{array}{l}\text { Ibu menentukan atau memilihkan channel Youtube yang } \\
\text { ditonton anak-anak mereka }\end{array}$ & $66 \%$ & $10 \%$ & $22 \%$ \\
\hline $\begin{array}{l}\text { Ibu mengawasi anak ketika mengakses Youtube } \\
\text { Intensitas Ibu memberikan instruksi terkait batasan konten } \\
\text { atau channel Youtube yang boleh ditonton }\end{array}$ & $81 \%$ & $12 \%$ & $5 \%$ \\
\hline $\begin{array}{l}\text { lbu melakukan diskusi dengan anak mengenai konten } \\
\text { channel Youtube yang telah ditonton }\end{array}$ & $65 \%$ & $33 \%$ & $2 \%$ \\
\hline
\end{tabular}

Table 4. Strategi pengamanan konten oleh ibu

\section{Alternatif Pengamana Konten Youtube bagi Anak}

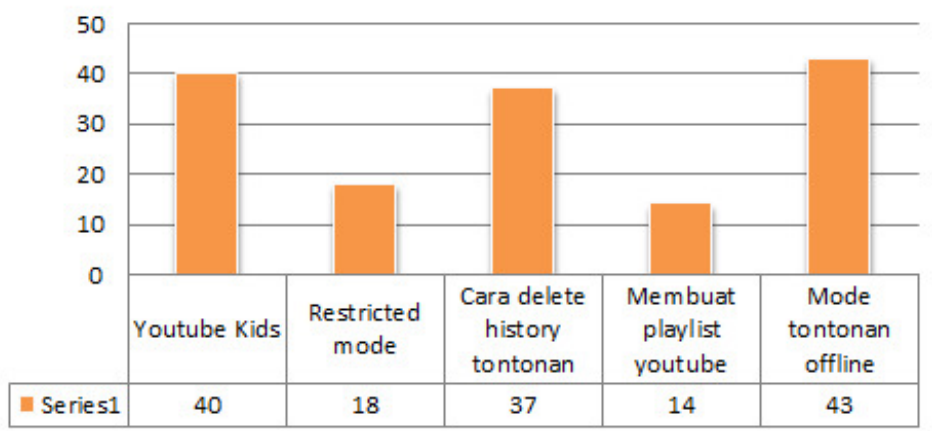

\section{E. BAHASAN}

Pada era digital yang serba maju hingga saat ini, dimana Youtube menjadi media yang umum dikonsumsi banyak orang, nyatanya masih ada ibu yang tidak memberi akses anaknya mengetahui apalagi mengkonsumsi tayangan-tayangannya. Dari data hasil penelitian tadi bisa diambil kesimpulan bahwa anak-anak sangatlah bergantung pada ibu mereka karena hanya bisa mengakses ketika didampingi ibu atau hari libur, itupun juga dengan pendampingan.

Mayoritas anak-anak masih menggunakan gadget orang tua mereka. Hal ini menguatkan penelitian sebelumnya oleh (Ofcom, 2019) yang telah dilakukan banyak negara bahwa anak-anak usia dibawah 13 tahun penggunaan gadget masih sangat dikendalikan orangtuanya dan hanya sebagian kecil saja yang diberi kepercayaan membawa atau memiliki gadget sendiri. Hal ini merupakan fenomena yang 5 hingga 10 tahun sebelumnya mungkin sangat jarang kita temui.
Anak-anak bisa mengakses Youtube saat hanya didampingi ibu, sebagian bisa bebas setiap hari dan sebagian lagi hanya boleh di akhir pekan atau hari libur sekolah. Media yang sering digunakan anak-anak dalam mengakses Youtube adalah dengan gadget atau handphone (walaupun milik ibu mereka), hal ini menguatkan penelitian sebelumnya oleh (Miner, 2015) dimana anakanak lebih tertarik menghabiskan waktu berjam-jam dengan gadget mereka untuk menikmati streaming video dibandingkan dengan melihat TV.

Motivasi atau tujuan terbesar anakanak menikmati tayangan-tayangan dari Youtube adalah hiburan. Selain itu, untuk mengerjakan tugas (PR), agar anak tidak rewel atau menangis dan untuk belajar mengenai sesuatu yang baru seperti tutorial (how to). Hal ini sejalan dan mendukung data hasil temuan penelitian sebelumnya dari (Putra \& Patmaningrum, 2018). Dengan ruang gerak yang terbatas, anak-anak masih mengkonsumsi konten-konten yang ramah anak seperti berbagai kartun, youtube kids, vlog dan lain sebagainya yang ramah 
anak. Tentu tidak mengejutkan hal ini bisa terjadi, karena saat anak-anak menonton ibu senantiasa mendampingi.

Dari segi pola pendampingan yang dilakukan oleh ibu bekerja, dimana mereka memiliki tantangan kesibukan kerja dan lebih sedikit waktu yang tersedia untuk berinteraksi dengan anak nyatanya tidak membuat mereka lengah untuk mendampingi anak dalam mengkonsumsi media massa Youtube. Belum ada penelitian sebelumnya secara detail tentang pola pendampingan yang dilakukan ibu pekerja, namun temuan dari (Irmayanti, 2018) tentang peran orang tua dalam mendampingi penggunaan gawai pada anak usia prasekolah menunjukkan bahwa ibu yang memiliki latarbelakang pendidikan tinggi cenderung memiliki cara-cara yang menarik.

Status yang berbeda dalam responden penelitian ini, dimana seluruh responden dari Irmayanti (2018) adalah ibu rumah tangga yang tidak bekerja namun cara yang digunakan sama saja. Hal itu berupa turut bermain gadget bersama-sama dengan anak agar lebih mudah mengarahkan konten yang aman dikonsumsi, menerapkan aturan intensitas baik itu dari segi durasi.

Model pendampingan lbu bekerja pada anak untuk mengakses Youtube yang ada dalam penelitian ini sejenis dengan model yang dibuat (Claretta \& Arianto, 2018). Penelitian Claretta dan Arianto (2018) fokus kepada pendampingan menggunakan internet secara umum. Walaupun begitu, temuan dalam penelitian ini tidak jauh berbeda. Ibu kerap membuat aturan menonton baik dalam bentuk batasan durasi jam, frekuensi dalam sepekan, dan menentukan channel yang bisa diakses anak. Yang tidak dijelaskan dalam penelitiannya adalah diskusi yang terjadi adalah diskusi anatara ibu dengan anak setiap setelah atau saat menonton tayangan YouTube. Juga ternyata, dengan tingginya pendampingan yang dilakukan ibu terhadap anak, ibu juga mengetahui banyak cara agar anak mengakses konten-konten yang aman dikonsumsi pada usianya.
Para ibu yang bekerja (working mom) lebih nyaman menggunakan strategi tontonan offline dan akses menggunakan Youtube Kids daripada mengatur playlist tontonan dan restricted mode. Mayoritas ibu juga familiar dengan menghapus history tontonan karena agar anak tidak juga mengkonsumsi tayangan yang ditonton ibunya dimana hal ini sangat mungkin terjadi mengingat anak mengakses Youtube menggunakan gadget ibu mereka. Dengan begitu, tetap saja memiliki kemungkinan anak menonton tayangan yang biasa ditonton orangtuanya, karena Youtube akan memunculkan genre tayangan yang biasa ditonton di halaman home. Maka pendampingan tentu sangat baik dilakukan.

Dalam penjelasan ini, kami melakukan korespondensi tambahan berupa interview dengan $10 \%$ dari sample partisipan yang kami miliki. Hasilnya mereka menyatakan bahwa memilihkan konten terhadap anakanak mereka dimulai dengan permintaan anak-anak, dan para ibu memilah apakah konten tersebut layak tonton atau tidak.

Mereka juga menyatakan jikapun konten-konten tersebut tidak layak tonton, maka para ibu akan memberikan dampingan dan nasihat serta diskusi mengapa konten tersebut dapat dilihat maupun tidak baik untuk di tonton. Hal ini sebanding dengan pernyataan responden dimana $82 \%$ dari para ibu pekerja menyatakan bahwa mereka melakukan pengawasan penuh pada anakanak mereka dalam akses YouTube.

\section{F. KESIMPULAN}

Media sosial Youtube dan internet akan selalu ada seiring tumbuh kembangnya masyarakat serta teknologi karena hal tersebut merupakan bagian dari budaya yang tidak bisa terhindarkan. Ibu yang bekerja memang memiliki waktu terbatas untuk berinteraksi dengan anak dan pendampingan yang tidak full time seperti ibu rumah tangga. Namun, dengan latar belakang pendidikan yang tinggi dan komitmen ibu untuk memberikan pendampingan dan mengontrol konten yang ditonton sangat memungkinkan agar 
anak terhindarkan dari dampak negatif Youtube.

Penelitian berikutnya sebaiknya menggali dampak-dampak dari konsumsi Youtube pada keluarga-keluarga yang sudah melakukan pendampingan secara tepat. Bukan hal yang tidak mungkin anak-anak mengakses konten Youtube tanpa sepengetahuan orang tua. Jadi, responden penelitian selanjutnya sebaiknya menjadikan anak-anak sebagai objek penelitian dengan tema yang sama. Apakah mereka benar-benar terhibur, dan benarbenar terhindarkan dari dampak buruk konten yang bukan diperuntukkan untuk mereka.

\section{REFERENSI}

Ayodele, A., Mosunmola, A., Senanu, K., \& Aderonke, N. (2015). Social Networking and Students' Academic Performance: the Role of Attention Deficit, Predictors of Behavior and Academic Competence. Retrieved from http://eprints.covenantuniversity.edu. ng/5336/1/Paper 72.pdf

Campbell, A. J. (2017). Rethinking Children's Advertising Policies for the Digital Age. Retrieved from https://scholarship.law.georgetown.edu/facpub/1945https://ssrn. com/abstract $=2911892$

Claretta, D., \& Arianto, I. D. (2018). Pendampingan Ibu pada Anak Dalam Pengggunaan Internet. Ilmu Komunikasi, 16, 129-137.

Digital 2019: Indonesia - DataReportal - Global Digital Insights. (2019). Retrieved January 23, 2020, from https://datareportal.com/reports/digital-2019-indonesia

Godawa, G., Gurba, E., Rzewucka, P., Tabor, M., \& Gurba, K. (2019). the Use of Social Media and the Youth'S Experience of Gratitude. INTED2019 Proceedings, 1(April), 34333439. https://doi.org/10.21125/inted.2019.0890

Guan, S.-S. A., \& Subrahmanyam, K. (2009). Youth Internet use: risks and opportunities. https://doi.org/10.1097/YCO.0b013e32832bd7e0

Helsper, E. J., Kalmus, V., Hasebrink, U., Sagvari, B., \& De Haan, J. (2013). Young children and their internet use Zero to Eight. Retrieved from http://eprints.Ise.ac.uk/id/ eprint/42872

Indonesian Digital Mums Survey 2017 by theAsianparent - issuu. (n.d.). Retrieved January 23, 2020, from https://issuu.com/theasianparent/docs/tap_survey_report-110917

Irmayanti, Y. (2018). Peran Orangtua dalam Mendampingi Penggunaan Gawai pada Anak Usia Prasekolah.

Littlejohn, S. W., Foss, K. A., \& Oetzel, J. G. (2017). Theories of Human Communication. In Journal of Chemical Information and Modeling (Eleventh E, Vol. 53). https://doi. org/10.1017/CBO9781107415324.004

Livingstone, S. (2012). Critical reflections on the benefits of ICT in education. Oxford Review of Education, 38(1), 9-24. https://doi.org/10.1080/03054985.2011.577938

Livingstone, S., Kirwil, L., Ponte, C., \& Staksrud, E. (2013). In their own words: What bothers children online? Retrieved from www.eukidsonline.net

Manning, J. (2014). Definition and Classes of Social Media. Encyclopedia of Social Media and Politics, (January). https://doi.org/10.4135/9781452244723.n485

Mas, P., Hanisshya, M. H., Lukman, Z., Normala, R., Azlini, C., \& Kamal, M. (2018). Internet Addiction among Secondary School Students in. International Journal of Research 
and Innovation in Social Science (IJRISS) |Volume, II, 2454-6186. Retrieved from www. rsisinternational.org

Miner, R. (2015). TV is Now the 2nd Screen for Kids - Digital Content Next. Retrieved January 23, 2020, from https://digitalcontentnext.org/blog/2015/07/14/tv-is-now-the-2ndscreen-for-kids/

Mulyono. (2016). FORUM GURU: Peran Pendidikan Keluarga di Era Digital - Tribun Jateng. Retrieved January 30, 2020, from https://jateng.tribunnews.com/2016/04/12/forumguru-peran-pendidikan-keluarga-di-era-digital

Ofcom. (2019). Children and Parents Media Use and Attitudes.

Orphanides, K. . (2018). YouTube for Kids is still is still churning out blood, suicide and cannibalism | WIRED UK. Retrieved January 23, 2020, from https://www.wired.co.uk/ article/youtube-for-kids-videos-problems-algorithm-recommend

Putra, A., \& Patmaningrum, D. A. (2018). Pengaruh Youtube di Smartphone Terhadap Perkembangan Kemampuan Komunikasi Interpersonal Anak. Jurnal Penelitian Komunikasi, 21(2), 159-172. https://doi.org/10.20422/jpk.v21i2.589

Putri, D., \& Kusbaryanto. (2012). Perbedaan Hubungan antara Ibu Bekerja dan Ibu Rumah Tangga terhadap Tumbuh Kembang Anak Usia 2-5 Tahun. Mutiara Medika, 12(3), 143-149. Retrieved from http://journal.umy.ac.id/index.php/mm/article/ download/1032/1117

Rahmat, S. T. (2018). POLA ASUH YANG EFEKTIF UNTUK MENDIDIK ANAK DI ERA DIGITAL. Retrieved from https://kbbi.web.id/orang-tua

Rossi, E. S. (n.d.). Uses \& Gratification/Dependency Theory. Retrieved January 23, 2020, from http://zimmer.csufresno.edu/ johnca/spch100/7-4-uses.htm

Taylor, S. (2017). Smartphone Addiction May Cause Brain Imbalance|RSNA 2017. Retrieved January 23, 2020, from https://rsna2017.rsna.org/dailybulletin/index.cfm?pg=17fri08

Tur-Viñes, V., Núñez-Gómez, P., \& González-Río, M. (2018). Kid influencers on YouTube. A space for responsibility. https://doi.org/10.4185/RLCS-2018-1303en 